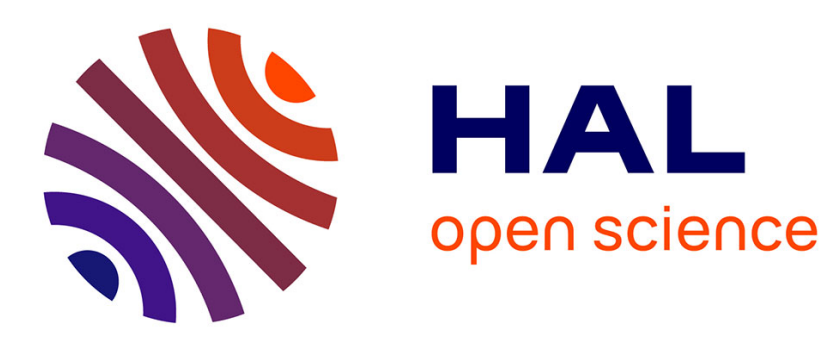

\title{
Demonstration of Radiation Efficiency Improvement of a Miniature Narrow Band Antenna
}

François Sarrazin, Sylvain Pflaum, Christophe Delaveaud

\section{To cite this version:}

François Sarrazin, Sylvain Pflaum, Christophe Delaveaud. Demonstration of Radiation Efficiency Improvement of a Miniature Narrow Band Antenna. 2018 IEEE International Symposium on Antennas and Propagation \& USNC/URSI National Radio Science Meeting, Jul 2018, Boston, United States. pp.1659-1660, 10.1109/APUSNCURSINRSM.2018.8608973 . hal-02077891

\section{HAL Id: hal-02077891 \\ https://hal.science/hal-02077891}

Submitted on 24 Mar 2019

HAL is a multi-disciplinary open access archive for the deposit and dissemination of scientific research documents, whether they are published or not. The documents may come from teaching and research institutions in France or abroad, or from public or private research centers.
L'archive ouverte pluridisciplinaire HAL, est destinée au dépôt et à la diffusion de documents scientifiques de niveau recherche, publiés ou non, émanant des établissements d'enseignement et de recherche français ou étrangers, des laboratoires publics ou privés. 


\title{
Demonstration of Radiation Efficiency Improvement of a Miniature Narrow Band Antenna
}

\author{
Francois Sarrazin, Sylvain Pflaum and Christophe Delaveaud \\ CEA-LETI, Minatec Campus \\ GRENOBLE-ALPES UNIVERSITÉ \\ Grenoble, France \\ christophe.delaveaud@cea.fr
}

\begin{abstract}
This paper investigates two ways to improve the radiation efficiency of an electrically small antenna loaded by a capacitor. The first one consists in enlarging the antenna strip width in order to lower its loss resistance. The second one focus on optimizing the loading capacitor used to lower the resonant frequency by mixing a discrete and a coplanar twin strip capacitors. The two studied parameters have a strong impact on the radiation efficiency as the antenna is electrically small.

Index Terms-electrically small antenna, radiation efficiency
\end{abstract}

\section{INTRODUCTION}

Electrically Small Antennas (ESAs) have been of interest for decades since early works by Wheeler [1] and Chu [2]. Most recent studies focus on antenna miniaturization while keeping low the Q-factor in order to maintain the bandwidth [3]. However, in the ever growing context of the Internet of Things, and especially Wireless Sensor Networks, low power sensors that transmit only a few packets of data have become necessary. Thus, it brings the need for miniature antennas with high radiation efficiency but with no tradeoff regarding the bandwidth and so the Q-factor [4]. In this paper, we present two different techniques aiming to improve the radiation efficiency of an ESA. The first approach consists in modifying the antenna strip width to limit the antenna loss resistance while the second one lays on the use of discrete capacitor components instead of the distributed one. In section II, we first introduce a miniature antenna design inspired from IFA. Then, the section III presents the two different approaches to improve the radiation efficiency of this antenna.

\section{Electrically Small Antenna Design}

The considered antenna is presented in Fig. 1. It is a balanced antenna that operates at $433 \mathrm{MHz}$ whose outer diameter is $50 \mathrm{~mm}(\lambda / 14)$ and copper strip is $1.6 \mathrm{~mm}$ wide etched on a low loss dielectric substrate (RO 3003). It combines different miniaturization techniques. The two $\lambda / 4$ arms are circularly folded to comply with the Chu form factor and they are terminated by a coplanar twin line capacitor to artificially extend their lengths and substantially lower the resonant frequency. Finally, the short-circuit is used to match the antenna input

This work was supported in part by the French Research Agency (ANR) under the "SENSAS" project (ANR-13-INFR-0014).

F. Sarrazin was with the CEA-LETI, Grenoble, France. $\mathrm{He}$ is now with the ESYCOM laboratory, Champs sur Marne, France (e-mail: francois.sarrazin@u-pem.fr).

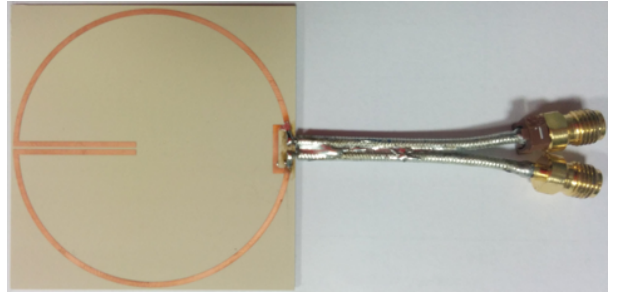

Fig. 1: Picture of the realized electrically small antenna fed by joint coaxial cables used for experimental characterization.

impedance to $50 \Omega$. The antenna is simulated with ANSYS [6] and measured using a differential measurement setup [7]. Simulated and measured input impedances are not shown here for brevity but are in very good agreement. The simulated radiation efficiency is equal to $44 \%$ while $39 \%$ are obtained from radiation measurement performed in anechoic chamber using the differential probe and a compact RF to optical transducer to minimize the influence of the measurement setup.

\section{RADIATION EFFICIENCY IMPROVEMENT}

In this section, we investigate two different ways to improve the radiation efficiency of the considered antenna.

\section{A. Strip width enlargement}

In this part, we change the copper strip width in order to modify the antenna loss resistance and thus optimize the antenna radiation efficiency. Indeed, the loss resistance $R_{\text {loss }}$ of a dipole antenna (assuming a sinusoidal current distribution) is given by

$$
R_{\text {loss }}=\frac{l}{4 \pi r} \sqrt{\frac{\omega \mu_{0}}{2 \sigma}}
$$

where $l$ is the dipole length, $\omega$ the angular frequency, $\mu_{0}$ the free space permeability, $\sigma$ the material conductivity and $r$ the dipole radius that is equivalent to the strip width for our planar case. Thus $R_{\text {loss }}$ is inversely proportional to the strip width. Several strip widths from $0.1 \mathrm{~mm}$ to $4.1 \mathrm{~mm}$ are considered in simulation. For each configuration, the length of the capacitor is adjusted in order to keep the resonant frequency the same. Three configurations have been realized and measured: $0.6 \mathrm{~mm}, 1 \mathrm{~mm}$ and $1.6 \mathrm{~mm}$, as presented in Fig. 2. The antenna radiation efficiency is presented in Fig. 3 


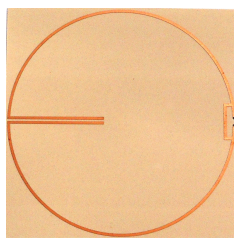

(a) $0.6 \mathrm{~mm}$

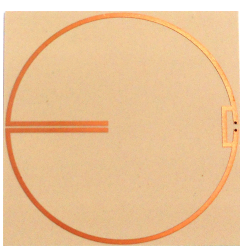

(b) $1 \mathrm{~mm}$

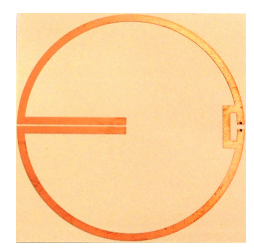

(c) $1.6 \mathrm{~mm}$
Fig. 2: The three realized antennas with different strip widths.

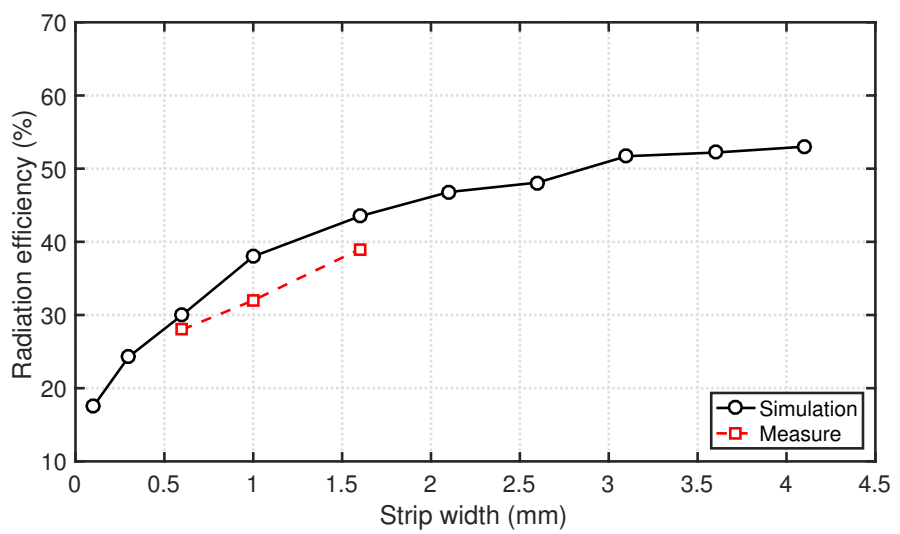

Fig. 3: The antenna radiation efficiency as a function of the strip width. Simulation and measurement.

as a function of the strip width. We can see that it increases up to $53 \%$ for the thickest strip width. We can also notice that this maximum value is obtained from $3.1 \mathrm{~mm}$ and there is not much variation for thicker strip, as parasitic effects between the antenna and the capacitor appear.

\section{B. Capacitor}

The significant role of the limited conductivity of the copper stripline suggests to replace the twin line capacitor by a discrete CMS-like capacitor and to study the influence of the Equivalent Series Resistance (ESR) of such capacitor on the antenna radiation efficiency. For the antenna whose strips are $1.6 \mathrm{~mm}$ wide, the original twin line capacitor of length $22 \mathrm{~mm}$ (Fig. 4e) is equivalent to a capacitance of $0.87 \mathrm{pF}$ (Fig. 4a). We also consider three intermediate cases where the two types of capacitor are placed in parallel to obtain a constant capacitance of $0.87 \mathrm{pF}$ (Fig. 4b to Fig. 4d). The simulated radiation efficiencies obtained for the five different configurations are presented in Fig. 5 as a fonction of the ESR from $0 \Omega$ to $1 \Omega$. The case " $22 \mathrm{~mm}$ " is constant to $44 \%$ as a function of the ESR as there is no discrete component for this configuration (twin line capacitor only). As expected, for an ESR equal to $0 \Omega$ (lossless discrete capacitor), the radiation efficiency is the highest for the purely discrete capacitance. Then, the radiation efficiency decreases as a function of the ESR but with various slopes. Thus, it is possible to find the right combination that can improve the original radiation efficiency. For example, for the $15 \mathrm{~mm}$ case, the radiation efficiency is higher than the $44 \%$ for all ESR up to $1 \Omega$.

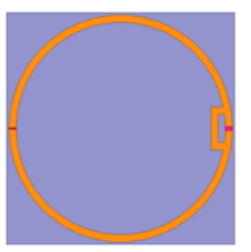

(a) $0 \mathrm{~mm}+0.87 \mathrm{pF}$

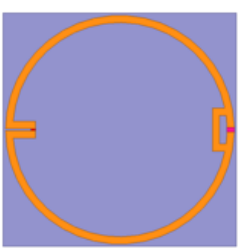

(b) $5 \mathrm{~mm}+0.67 \mathrm{pF}$

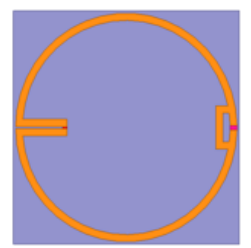

(c) $10 \mathrm{~mm}+0.47 \mathrm{pF}$

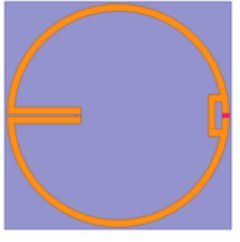

(d) $15 \mathrm{~mm}+0.27 \mathrm{pF}$

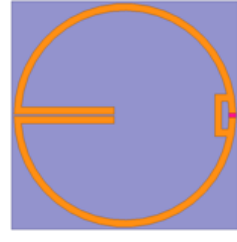

(e) $22 \mathrm{~mm}$
Fig. 4: The antenna for the five capacitor configurations.

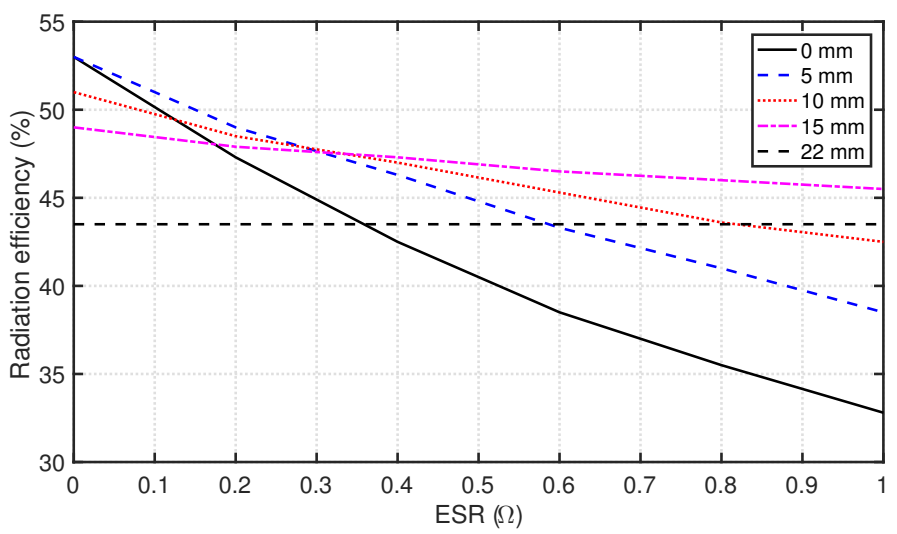

Fig. 5: Radiation efficiency as a function of the capacitor ESR for the five different configurations.

\section{CONCLUSION}

In this paper, we presented two approches to improve the radiation efficiency of a miniature antenna. Simulation and experimental results demonstrate the capabilities of the efficiency enhancement for constant antenna size. The fundamental laws of ESAs remain nonetheless verified because the efficiency increase is obtained at the expense of the bandwidth.

\section{REFERENCES}

[1] H. A. Wheeler, "Fundamental limitations of small antennas," Proc. IRE, vol. 35, pp. 1479-1484, 1947.

[2] L. J. Chu, "Physical limitation on omnidirectional antennas," Journal of Applied Physics, vol. 19, pp. 1163-1175, 1948.

[3] N. Behdad, K. Sarabandi, "Bandwidth enhancement and further size reduction of a class of miniaturized slot antennas," IEEE Trans. Antennas Propag., vol. 52, no. 8, pp. 1928-1935, Aug. 2004.

[4] F. Sarrazin, S. Pflaum and C. Delaveaud, "Radiation Efficiency Improvement of a Balanced Miniature IFA-Inspired Circular Antenna," IEEE Antennas Wireless Propag. Lett., vol. 16, pp. 1309-1312, 2017.

[5] F. Sarrazin, S. Pflaum and C. Delaveaud, "Radiation efficiency measurement of a balanced miniature IFA-inspired circular antenna using a differential Wheeler cap setup," Int. Workshop on Antenna Technology, Cocoa Beach, FL, pp. 64-7, 2016.

[6] ANSYS Electromagnetics Suite, Release 16.0.

[7] R. Meys and F. Janssens, "Measuring the impedance of balanced antennas by an S-parameter method," IEEE Antennas Propag. Mag., vol. 40 , no. 6 , pp. 62-65, Dec. 1998. 